Original article

\title{
THE EFFECT OF SALT-FREE - SALT DIET ON THE REPRODUCTIVE PERFORMANCE OF ILE DE FRANCE EWES
}

\author{
N. METODIEV ${ }^{1}$, D. DIMOV ${ }^{2}$, I. RALCHEV ${ }^{2}$, E. RAICHEVA ${ }^{1} \&$ M. IGNATOVA ${ }^{1}$ \\ ${ }^{1}$ Institute of Animal Science, Kostinbrod, Bulgaria; ${ }^{2} \mathrm{Faculty}$ of Veterinary Medicine, \\ University of Forestry, Sofia, Bulgaria
}

\section{Summary}

Metodiev, N., D. Dimov, I. Ralchev, E. Raicheva \& M. Ignatova, 2019. The effect of saltfree - salt diet on the reproductive performance of Ile de France ewes. Bulg. J. Vet. Med., 22, No 1, 82-90.

The aim of the present study was to establish the effect of salt-free - salt diet (SFSD) on the size of antral follicles during salt consumption, the duration of controlled breeding campaign and the fertilities of ewes from the Ile de France breed. The experiment was carried out with 57 ewes, which were divided into 3 groups (19 ewes in each) depending on whether they were subjected to SFSD and their contacts with rams during the first 8 days of the beginning of breeding: Group I - SFSD + ram contact; Group II - only SFSD; Group III - no SFSD, only ram contacts. The first day of the salt diet coincided with the first day of ram contacts. Transrectal ultrasound examinations of the ovaries were done on days 1, 2, 3, 5, 6 and 7. The time of manifestation of estrus (in days), pregnancy rate and fecundity were studied. A significant effect of time $(\mathrm{P}<0.05)$ and diet $(\mathrm{P}<0.01)$ on the size of follicles was established. The onset of the first estrus, the shortest terms of breeding campaign, the fertility and the fecundity results gave us reason to favour the scheme applied to Group II. A stimulatory effect of the diet in that study was demonstrated, but the pattern was different from our previous studies.

Key words: estrus, ewes, fertility, follicles, salt

\section{INTRODUCTION}

The synchronisation of fertility and lambing of ewes is one of the main elements in the reproductive management in sheep breeding. The methods of estrus synchronisation can be classified as natural (nonhormonal) and pharmacological (hormonal). Non-pharmacological methods are alternative to the conventional estrus synchronisation, an important issue in today's consumer attitudes (Martin et al., 2004). The most popular non-pharmacological methods are: the ram effect, flushing, saltfree-salt diet (SFSD), vitamin and mineral supplementation (Tyankov et al., 2000).

The introduction of $\mathrm{ram}(\mathrm{s})$ (i.e. ram effect) to isolated anoestrus ewes leads to increase of pulsatile secretion of $\mathrm{LH}$, which may end with LH surge followed by ovulation (Knight et al., 1978; Oldham \& Cognié, 1980; Martin et al., 1983; Ungerfeld et al., 2004). The ram effect can be achieved without prior isolation of ewes 
from rams (Cusha et al., 1992). It is applicable in breeding season too, as the introduction of rams to cyclic ewes stimulates an increase in pulsatile LH secretion, independent of ewe genotype or stage of the estrous cycle (Hawken et al., 2007). Ewes generally ovulate in response to ram introduction within $54 \mathrm{~h}$ (Oldham et al., 1978), but the first ovulation following introduction of rams is usually not accompanied by behavioural estrus (Oldham \& Cognié, 1980; Nugent et al., 1988). In some ewes there is an initial short luteal phase of 4-5 days, then a second ovulation without any signs of estrus, followed by a luteal phase of normal duration (Ungerfeld et al., 2004). These differences of ovarian response at ewes could lead to two surges of manifesting synchronised estrus induced by the ram effect - the first is between days $17-20$ and the second is between days 21-25 after ram introduction (Martin et al., 1986).

The method of salt-free - salt diet has been traditionally used in Bulgaria at the beginning of breeding season. The traditional use of the SFSD comprises starting with salt-free diet for 6 or 7 days, followed by salt diet of the same duration with a daily dose of salt $(\mathrm{NaCl}) 15-20 \mathrm{~g}$ per ewe (Solomonov, 1977; Tsolov et al., 2000; Hristova, 2007). The effect of SFSD is $40-50 \%$ of ewes coming in estrus during the first week from the start of the breeding campaign (Tyankov et al., 2000). For the last 10 years, series of experiments were done with the aim to test the effect of the diet or the diet as a part of estrus synchronisation protocols. The obtained results were contradictory and up to now there are not convincing grounds accept or reject the SFSD (Metodiev, 2013). Nedelkov \& Todorov (2012) and Nedelkov et al. (2012) investigated the effect of salt-free - salt diet and concluded there it had no effect, whereas Hristova (2007), Metodiev et al., (2007; 2009; 2010), Metodiev (2014) reported satisfying results in line with data reported by Tyankov et al. (2000).

The aim of the present study was to establish the effect of salt-free - salt diet on the size of antral follicles during salt consumption, the duration of controlled breeding campaign and the fertility of ewes from the Ile de France breed.

\section{MATERIALS AND METHODS}

The experiment was carried out in March (second half), April, May (first half) of 2014, with 57 clinically healthy Ile de France ewes (aged 3-4 years), raised in the experimental base of the Institute of Animal Science - Kostinbrod. Ewes were with BCS of 3.0-3.5 and live weight between $70-80 \mathrm{~kg}$. All ewes had normal previous lambing (lambed during October 2013) and lambs were weaned at midJanuary 2014. In previous works of ours (Metodiev et al., 2010; Metodiev \& Raicheva, 2011) and also our field experience since 2005 with Ile de France ewes from the flock of IAS-Kostinbrod, we successfully fertilised them without hormonal stimulation by that time of the year (spring, April-May). So the experiment was designed to start in the beginning of the breeding season.

Ewes were fed (per ewe): meadow hay $0.7 \mathrm{~kg}$, corn silage $-1.5-2.0 \mathrm{~kg}$ and concentrate $(0.150 \mathrm{~kg}$ dried distiller's grain solubles and $0.150 \mathrm{~kg}$ wheat grain). After the second half of April (grazing on pasture about 2-3 hours per day), the feeding with hay was stopped, but the feeding with corn silage and concentrate was the same. The salt diet, preceded by 10 days of saltfree diet (which means that the whole saltlicks were removed and the ewes didn't 
consume any salt), continued with 7 days during which the salt licks were returned and salt was added in the concentrate at a daily dose of $20 \mathrm{~g}$ per ewe. The ewes were divided into 3 groups (19 ewes in each) according to whether they were subjected to SFSD and their contacts with rams during the first 8 days of the beginning of breeding: Group I - SFSD + ram contact; Group II - only SFSD; Group III - no SFSD, only ram contacts. The first day of the salt diet coincided with the first day of ram contacts (also the start of the breeding campaign (BC).

Transrectal ultrasound examinations of the ovaries were done on randomly selected 15 ewes (5 ewes from each group) on days 1, 2, 3, 5, 6 and 7 of the salt diet. Follicles with diameter $\geq 3.0 \mathrm{~mm}$ and corpora lutea were counted and measured. Day 4 was skipped due to technical reasons. The ultrasound screenings were performed in the morning, after that the ewes consumed salt, mixed with wheat grains and DDGS (Group III did not receive salt with the mix). Ultrasound examinations were conducted in standing position of the ewes. First the ampulla recti was evacuated from faeces, after that the ultrasound probe, covered with gel, was inserted with the help of a cradle into the rectum. The equipment included a digital portable ultrasound system ALOKA ProSound 2 (Aloka Co., Ltd.) supplied with electronic linear transducer UST 5820, with frequency of $7.5 \mathrm{MHz}$. After concentrate intake, teasers were introduced to ewes (1 teaser to 20 ewes). After the $8^{\text {th }}$ day all ewes were mixed with ewes from the flock and the ewes in estrus were detected by teasers once daily in the morning for 11.5 hour (1 teaser for 50 ewes). Ewes from Group II were put in contact with rams on day 9 after the beginning of the experiment. Experimental ewes in heat were inseminated naturally, once in the middle of the day, when they manifested estrus. Six clinically healthy rams at the age between 1.5 and 5 years were used, one ram performing maximum 3 servings per day.

The following reproductive traits were studied: the time of manifestation of estrus (in days), pregnancy rate and fecundity.

Breeding and estrus observation by teasers for Group I and Group III started at Day 1 of the salt diet. The first day of the salt diet coincided with the first day, in which ewes contacted the rams (for Group I and Group III). Breeding and estrus observation by teasers for Group II started at the second day after the end of the salt diet e.g. day 9 of the breeding of Group I and Group III. For the first 8 days they were tested for presence of heat with an estrus detector (Draminski Ltd). All ewes that had electrical resistance $\leq 350$ units were considered to be in estrus (according to user's manual and our field observations with ewes in estrus, previously detected by teasers). The experiment lasted till all experimental ewes having manifested estrus for the first time.

Fertility (at first estrus) was defined as the ratio of the number of pregnant ewes to the number of ewes in the group. Fecundity was defined as the number of lambs born from pregnant ewes (including all born lambs - live born, dead born and aborted).

A linear mixed model was developed in which the dependent variable was the size of follicles, independent variables were the group and time. The random time effect and intercept were included. The fixed effect was associated with the group and time. The restricted maximum likelihood method for the analysis of data is used. One-way ANOVA and post hoc LSD analysis were used to compare the 
Table 1. Ovarian structures (mean $\pm \mathrm{SEM}$ ) in the three groups of sheep (I: salt-free-salt diet + ram contact; II: salt-free-salt diet only; III: ram contact only) according to the time of examination

\begin{tabular}{|c|c|c|c|c|c|}
\hline \multirow{3}{*}{ Time } & \multirow{3}{*}{ Groups } & \multicolumn{4}{|c|}{ Ovarian structures } \\
\hline & & \multicolumn{2}{|c|}{ Follicles, $\mathrm{cm}$} & \multicolumn{2}{|c|}{ Corpora lutea, $\mathrm{cm}$} \\
\hline & & $\mathrm{n}$ & size, $\mathrm{cm}$ & $\mathrm{n}$ & size, $\mathrm{cm}$ \\
\hline \multirow{3}{*}{ Day 1} & SFSD+ram contact & 14 & $0.51 \pm 0.09$ & 2 & $0.45 \pm 0.05$ \\
\hline & SFSD & 9 & $0.59 \pm 0.21^{*}$ & 1 & 0.5 \\
\hline & Ram contact & 17 & $0.44 \pm 0.09^{\mathbf{A}}$ & 0 & \\
\hline \multirow{3}{*}{ Day 2} & SFSD+ram contact & 14 & $0.52 \pm 0.11$ & 2 & $0.47 \pm 0.05$ \\
\hline & SFSD & 12 & $0.57 \pm 0.25$ & 1 & 0.53 \\
\hline & Ram contact & 16 & $0.60 \pm 0.12^{\mathbf{B}}$ & 0 & \\
\hline \multirow{3}{*}{ Day 3} & SFSD+ram contact & 13 & $0.58 \pm 0.15$ & 3 & $0.43 \pm 0.05$ \\
\hline & SFSD & 11 & $0.69 \pm 0.20$ & 0 & \\
\hline & Ram contact & 9 & $0.56 \pm 0.11$ & 3 & $0.43 \pm 0.02$ \\
\hline \multirow{3}{*}{ Day 5} & SFSD+ram contact & 12 & $0.49 \pm 0.16$ & 2 & $0.36 \pm 0.02$ \\
\hline & SFSD & 14 & $0.56 \pm 0.18$ & 5 & $0.45 \pm 0.02$ \\
\hline & Ram contact & 16 & $0.52 \pm 0.15$ & 5 & $0.41 \pm 0.03$ \\
\hline \multirow{3}{*}{ Day 6} & SFSD+ram contact & 10 & $0.60 \pm 0.11$ & 3 & $0.48 \pm 0.04$ \\
\hline & SFSD & 13 & $0.65 \pm 0.21$ & 5 & $0.47 \pm 0.02$ \\
\hline & Ram contact & 15 & $0.57 \pm 0.10$ & 4 & $0.54 \pm 0.05$ \\
\hline \multirow{3}{*}{ Day 7} & SFSD+ram contact & 14 & $0.58 \pm 0.10$ & 3 & $0.46 \pm 0.03$ \\
\hline & SFSD & 14 & $0.58 \pm 0.13$ & 3 & $0.51 \pm 0.05$ \\
\hline & Ram contact & 17 & $0.58 \pm 0.13$ & 3 & $0.48 \pm 0.01$ \\
\hline
\end{tabular}

* $\mathrm{P}<0.01$ between Group II and Group III; ${ }^{\mathbf{A}}$ statistically significant differences between the follicle size at day 1 and day $2(\mathrm{P}<0.001)$; day $3(\mathrm{P}<0.05)$; day $6(\mathrm{P}<0.01)$; day $7(\mathrm{P}<0.01)$; ${ }^{\mathbf{B}}$ statistically significant differences between follicle size at day 2 and day $5(\mathrm{P}<0.05)$.

size of follicles. All data were calculated by IBM SPSS 19.

\section{RESULTS}

A significant effect of time $(\mathrm{F}=4.273$, $\mathrm{P}<0.05)$ and diet $(\mathrm{F}=3.393, \mathrm{P}<0.01)$ on the size of follicles was established. Significant differences for the size of follicles were established only between Group II and III for day $1(\mathrm{P}<0.01, \mathrm{~F}=3.895)(\mathrm{Ta}-$ ble 1). The time had significant effect only on size of follicles of Group III ( $\mathrm{P}<0.01$, $\mathrm{F}=3.915$ ) (Table 1). For the studied period, ewes from Group II had follicles with the largest size - between 0.58 and $0.69 \mathrm{~cm}$ and also follicles with the maximum size - up to $1.2 \mathrm{~cm}$.
Most of the ewes came in estrus for the first time between days 15-27 of the beginning of breeding campaign (Group I - 12/19, Group II - 13/19, Group III 13/19). It should be noticed that the breeding campaign in Group II started 8 days later (on day 9) and this group had the shorter bounds of breeding - 23 days (Fig. 1).

The test with an estrus detector showed that for the first 8 days 8 ewes had signs of estrus without ram contacts. Five out of eight ewes came in estrus again in the interval 16-18 days, detected by teasers ( these were days 18-21 of the beginning of breeding campaign).

The fertility rates were high for all groups, but Group II had a fertility of 


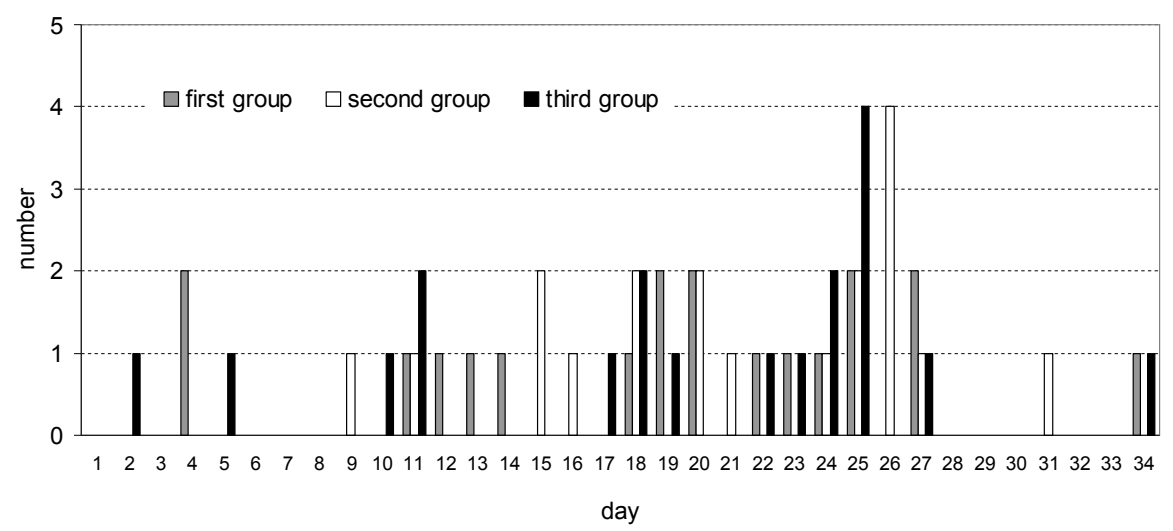

Fig. 1. Onset of first estrus in ewes detected by a teaser from the three experimental groups (first group: salt-free-salt diet + ram contact; second group: salt-free-salt diet only; third group: ram contact only).

Table 2. Fertility and fecundity of the three experimental groups of ewes (first group: salt-free-salt diet + ram contact; second group: salt-free-salt diet only; third group: ram contact only)

\begin{tabular}{lcrcc}
\hline \multirow{2}{*}{ Groups } & \multicolumn{2}{c}{ Fertility (at first estrus) } & \multicolumn{3}{c}{ Fecundity } \\
\cline { 2 - 5 } & \multicolumn{1}{c}{$\mathrm{n}$} & \multicolumn{1}{c}{$\%$} & $\mathrm{n}$ & $\%$ \\
\hline Group I & $16 / 19$ & 84.21 & 24 & 150.00 \\
Group II & $19 / 19$ & 100.00 & 31 & 163.16 \\
Group III & $16 / 19$ & 84.21 & 25 & 154.25 \\
\hline
\end{tabular}

$100 \%$ (every ewe conceived at first estrus, Table 2). The fecundity was similar among the groups, with the highest value in Group II - $163.16 \%$ (Table 2).

\section{DISCUSSION}

Significant differences in the size of follicles were established only between Group II and III for day $1(\mathrm{P}<0.01, \mathrm{~F}=3.895$; Table 2). We suppose that this may be due to a salt deficiency during the previous 10 days. It is acknowledged that the deficiency in sodium and associated excess of potassium can reduce fertility by irregular estrus cycles, endometritis and follicular cysts (Moinier \& Drüeke, 2008).
The significant effect of time on size of follicles for Group III $(\mathrm{P}<0.01$, $\mathrm{F}=3.915)$ was expected and corresponded to literature data for the pattern of follicle waves (Ginther et al., 1995; Bartlewski et al., 1998; 1999; Evans et al., 2000) and the data about the ram effect (Ungerfeld, 2003).

The results concerning follicle size of the other two groups were interesting. Both groups (I and II) during the whole studied salt period had follicles with a size near ovulation. Group II had follicles with the largest size - between 0.58 and 0.69 $\mathrm{cm}$ and also follicles with the maximum size - up to $1.2 \mathrm{~cm}$. These results meant that these follicles didn't ovulate and persisted. We could not tell that these folli- 
cles were cysts, because cysts are defined as large thin-walled follicular structures that do not ovulate but persist for at least 10 days in the absence of a corpus luteum (Kesler \& Garverick, 1982). In our case both groups had corpora lutea, so maybe there was no LH deficiency. Also after finishing the SFSD, the ewes showed normal cyclicity.

The pathophysiology underlying follicular cysts appears to be lack of an estradiol $\left(\mathrm{E}_{2}\right)$-induced $\mathrm{GnRH} / \mathrm{LH}$ surge due to hypothalamic insensitivity to $E_{2}$ (Gümen \& Wiltbank, 2005). There were ewes from Group II in estrus, so they should have high estradiol activity. On the other hand, ewes from Group I were in contact with rams, so they should have high LH levels. Due to both reasons we have hypothesised (Metodiev et al., 2009) that there was a synergic effect between ram effect (high LH release) and the saltfree - salt diet.

In our previous studies (Metodiev et al., 2009; 2010) we suggested that the synergic effect between the ram effect and SFSD leads to estrous behaviour in more than half of ewes from the studied groups. Ewes from Group I however didn't show this pattern. We supposed that this may be due to several reasons - behaviour of rams, breed, time of the year. The rams were with low levels of sexual pereformance (without enough sexual activity, in more cases the ewes first started a contact with the rams), hence they didn't induce a sufficient LH surge. It is known that rams that exhibit high compared to low levels of sexual performance (on the basis of serving capacity tests) induced a greater percentage of ewe's ovulations (Perkins \& Fitzgerald, 1994). Also, previous study with Ile de France and SPBM rams raised in IAS - Kostinbrod, showed that the former were in the intermediate group compared to the latter breed of rams, distinguished with high serving capacity (Kistanova et al., 2005).

Another reason was the weather. It may be a factor, because our previous studies were done during warmer months - May, June, July and August, whereas the present study was conducted in March and April. We obtained better results by using this protocol (during July and August) with SPBM ewes (Metodiev et al., 2009; Metodiev, 2014). The above mentioned considerations (behaviour of rams, breed, time of the year) should be taken into account in next studies.

It was surprising that the first estrus, terms of breeding campaign, pregnancy rate, and fecundity were the best in Group II. The shortest term of breeding campaing gave us reason to favour the scheme applied to Group II. Fertility and fecundity rates were similar in both groups. It is well known that after natural estrus (not induced by hormonal treatment) and natural matings, the fertility rates were the best.

Salinity is an increasing problem in agriculture worldwide (Ghassemi et al., 1995). One of the available options to revegetate salinised landscapes and reestablish grazing systems, is the use of halophytic plants such as saltbush (Masters et al., 2007). In terms of integrating saltbush into a productive system, Digby et al. (2008) showed that high salt intake did not decrease the reproductive capacity of the ewe. Personal communications with farmers in Bulgaria revealed that many practice so called ,provender" that means adding a high dose of salt in the concentrate once a week, especially when ewes graze on highland pastures or before preparing them for breeding.

We agree with the statement that the salt-free - salt diet acts as a stimulus on 
reproductive system (Bankov et al., 1989). Aristotle was perhaps the first to mention that sheep were in a better condition by keeping their hydro-mineral balance under control and said that the animals that drink saline water can copulate earlier (Moinier \& Drüeke, 2008). We demonstrated a stimulatory effect in our study, but its pattern was different from previous studies of ours. More experiments should be conducted to understand the mechanisms of that effect.

\section{ACKNOWLEDGEMENTS}

A part of this study was presented at the $19^{\text {th }}$ Conference of ESDAR, 12.09-14.09 Albena, Bulgaria as a poster entitled "The effect of salt consumption on the size of antral follicles at ewes" and authors M. Ignatova, N. Metodiev, D. Dimov, I. Ralchev and E. Raicheva.

\section{REFERENCES}

Bankov, N., L. Kanchev, L. Kostov \& K. Vlahov, 1989. Biology and biotechnology of reproduction of domestic animals, BAS Publishing House, Sofia, 73-74 (BG).

Bartlewski, P. M., A. P. Beard, S. J. Cook \& N. C. Rawlings, 1998. Ovarian follicular dynamics during anoestrus in ewes. Journal of Reproduction and Fertility, 113, 275-285.

Bartlewski P. M., A. P. Beard, S. J. Cook, R. K. Chandolia, A. Honaramooz \& N. C. Rawlings, 1999. Ovarian antral follicular dynamics and their relationships with endocrine variables throughout the oestrous cycle in breeds of sheep differing in prolificacy. Journal of Reproduction and Fertility, 115, 111-124.

Cushwa, W. T., G. E. Bradford, G. H. Stabenfeldt, Y. M. Berger \& M. R. Dally, 1992. Ram influence on ovarian and sexual activity in anestrus ewes: Effects of isolation of ewes from rams before joining and date of ram introduction. Journal of Animal Science, 70, 1195-1200.

Digby, S. N., D. G. Masters, D. Blache, M. A. Blackberry, P. I. Hynd \& D. K. Revell, 2008. Reproductive capacity of Merino ewes fed a high-salt diet. Animal, 2, 13531360.

Evans, A. C. O., P. Duffy, P. N. Hynes \& M. P. Boland, 2000. Waves of follicle development during the estrous cycle in sheep. Theriogenology, 53, 699-715.

Hawken, P. R., A. P. Beard, T. Esmaili, H. Kadakowa, A. C. O. Evans, D. Blanche \& G. B. Martin, 2007. The introduction of rams induces an increase in pulsatile $\mathrm{LH}$ secretion in cyclic ewes during breeding season. Theriogenology, 68, 56-66.

Hristova, C. P., 2007. Opportunities for controlling sexual activity of the ewes. $\mathrm{PhD}$ Thesis, Agricultural Academy, Research Institute of Mountain Stockbreeding and Agriculture, Troyan (BG).

Ghassemi F., A. J. Jakeman \& H. A. Nix, 1995. Salinisation of Land and Water Resources. CAB International Publishing, Wallingford, UK.

Ginther, O. J., K. Kot \& M. C. Wiltbank, 1995. Associations between emergence of follicular waves and fluctuations in FSH concentrations during the estrous cycle in ewes. Theriogenology, 43, 689-703.

Gümen, A. \& M. C. Wiltbank, 2005. Follicular cysts occur after a normal estradiolinduced $\mathrm{GnRH} / \mathrm{LH}$ surge if the corpus haemorrhagicum is removed. Reproduction, 129, 737-745.

Kesler, D. J. \& H. A. Garverick, 1982. Ovarian cysts in dairy cattle: A review. Journal of Animal Science, 55, 1147-1159.

Kistanova, E., V. Karcheva, A. Kolev \& E. Raicheva, 2005. Estimation of sexual activity of rams by serving capacity test. Animal Science (Sofia), XLII, 145-148.

Knight, T. W., A. J. Peterson \& E. Payne, 1978. The ovarian and hormonal response of the ewe to stimulation by ram early in the breeding season. Theriogenology, 10, 343 . 
Martin, G. B., R. J. Scaramuzzi \& D. R. Lindsay, 1983. Effect of the introduction of rams during the anestrous season on the pulsatile secretion of $\mathrm{LH}$ in ovariectomized ewes. Journal of Reproduction and Fertility, 67, 47-55.

Martin, G. B., C. M. Oldham, Y. Cognié \& D. T. Pearce, 1986. The physiological responses of anovulatory ewes to the introduction of rams - a review. Livestock Production Science, 15, 219-247.

Martin, G. B., J. T. Milton, R. H. Davidson, G. E. Banchero Hunzicker, D. R. Lindsay \& D. Blanche, 2004. Natural methods of increasing reproductive efficiency in sheep and goats. Nutritional and environmental effects on reproduction in small ruminants. Animal Reproduction Science, 82-83, 231-246.

Masters, D. G., S. E. Benes \& H. C. Norman, 2007. Biosaline agriculture for forage and livestock production. Agriculture, Ecosystems and Environment, 119, 234-248.

Metodiev, N., E. Raicheva \& I. Ralchev, 2007. The abilities for combinative treatment of nonhormonal and hormonal methods to achieve synchronized estrus at ewes from Ile de France breed. In: Proceedings from Scientific Conference "Tradition and Present State of Veterinary Medicine", University of Forestry, Sofia, pp. 171-176 (BG).

Metodiev, N., E. Raicheva \& I. Ralchev, 2009. Influence of the salt-free-salt diet and the ram effect on main reproductive traits of ewes from Synthetic Population Bulgarian Milk. Bulgarian Journal of Agricultural Science, 15, 598-603.

Metodiev, N., N. Todorov \& E. Raicheva, 2010. Sexual activity and use of nonhormonal methods for synchronization of fertilities and increasing litter size of ewes from Ile de France breed. Animal Science (Sofia), XLVII, 15-23 (BG).

Metodiev, N. \& E. Raicheva, 2011. Effect of the short-term progestagen treatments plus PMSG prior ram introduction on the estrus synchronization and the fertility of Ile de
France ewes in the beginning of mating season. Biotechnology in Animal Husbandry, 3, 1157-1166.

Metodiev, N., 2013. State and perspectives for development of the bulgarian studies, concerning control of fertilities of sheep. Journal of International Scientific Publications: Agriculture \& Food, 1, 47-57, https://www.scientific-publications.net/ download/agriculture-and-food-2013-2.pdf (15 June 2017 date last accessed).

Metodiev, N., 2014. Estrus synchronization of ewes by using single treatment with synthetic analogue of PGF2 $\alpha$. Agrarian Science, 47, 35-41 (BG).

Moinier, B. M. \& T. B. Drueke, 2008. Aphrotite, sex and salt - from butterfly to man. Nephrology Dialysis Transplantation, 23, 2154-2161.

Nedelkov, K., N. Todorov \& N. Vasilev, 2012. The possibility for oestrus synchronization by salt-free-salt diet in some sheep breeds reared in Bulgaria. Bulgarian Journal of Agricultural Science, 18, 942-952.

Nedelkov, K. \& N. Todorov, 2012. Infuence of the salt-free-salt diet on the synchronization of estrus in ewes from Bulgarian milk sheep population. Animal Science (Sofia), XLIX, 1-12 (BG).

Oldham, C. M. \& Y. Cognié, 1980. Do ewes continue to cycle after teasing? Proceedings of Australian Society of Animal Production, 13, 82.

Perkins A. \& J. A. Fitzgerald, 1994. The behavioral component of the ram effect: The influence of ram sexual behavior on the induction of estrus in anovulatory ewes. Journal of Animal Science, 72, 51-55.

Solomonov, H., 1997. Possibilities for increasing of the meat production from sheep, Thesis, SPU - "Cattle and sheep husbandry", Institute of Animal Science Kostinbrod, pp.100-145 (BG).

Tsolov, S., M. Dimitrov, P. Georgiev, I. Ivanov \& St. Yotov, 2000. Practical guide in veterinary obstetrics, gynecology and artificial insemination, Contrast Printing House, p. 28 (BG). 
The effect of salt-free - salt diet on the reproductive performance of Ile de France ewes

Tyankov, S., I. Dimitrov, I. Stankov, R. Slavov \& D. Panayotov, 2000. Sheep and Goat Breeding, Abagar, Veliko Tarnovo (BG).

Ungerfeld, R., M. Forsberg \& E. Rubianes, 2004. Overview of the response of anoestrus ewes to the ram effect. Reproduction, Nutrition and Development, 16, 479-490.

Paper received 23.12.2016; accepted for publication 07.04 .2017

\section{Correspondence:}

Nikola Metodiev PhD

Sheep Breeding Department, Institute of Animal Science,

Kostinbrod, Bulgaria

e-mail: n_metodiev@abv.bg 